\title{
Outcomes of a Series of Patients with Post- Prostatectomy Incontinence Treated with an Adjustable Transobturator Male System or Artificial Urinary Sphincter
}

\author{
Cristina Esquinas · Sonia Ruiz · Elena de Sancha · Mónica Vazquez • \\ Juan F. Dorado · Miguel Virseda · Ignacio Arance · Javier C. Angulo (D)
}

Received: October 10, 2020 / Accepted: November 4, 2020 / Published online: November 23, 2020

(C) The Author(s) 2020

\begin{abstract}
Introduction: A prospective evaluation of outcomes in a series of patients with post-prostatectomy incontinence (PPI) treated with two different devices is presented.

Methods: Consecutive patients with PPI underwent interventions with an adjustable transobturator male system (ATOMS) or artificial urinary sphincter (AUS). Decisions were based on patient preference after physician counselling. Patient characteristics and operative and postoperative parameters including dryness, satisfaction, complications, revision and device durability were evaluated.
\end{abstract}

Electronic supplementary material The online version of this article (https://doi.org/10.1007/s12325$020-01563-z)$ contains supplementary material, which is available to authorized users.

C. Esquinas - S. Ruiz - M. Virseda - I. Arance .

J. C. Angulo $(\bowtie)$

Department of Urology, Hospital Universitario de

Getafe, Getafe, Madrid, Spain

e-mail: javier.angulo@universidadeuropea.es;

jangulo1964@gmail.com

E. de Sancha - M. Vazquez - I. Arance - J. C. Angulo

Department of Medical Clinic, Faculty of

Biomedical Sciences, Universidad Europea de

Madrid, Madrid, Spain

J. F. Dorado

PeRTICA Análisis Estadísticos S.L., Getafe, Madrid, Spain
Results: One hundred twenty-nine patients were included: $102(79.1 \%)$ received ATOMS and $27(20.9 \%)$ AUS. Mean follow-up was $34.9 \pm 15.9$ months. No difference was observed between patient age $(p=0.56)$, ASA score $(p=0.13)$, Charlson index $(p=0.57)$ and radiation $(p=0.3)$. BMI was higher for AUS (27.1 vs. $29.7 ; p=0.003$ ) and also baseline incontinence severity $(7.9 \%$ mild, $44.1 \%$ moderate and $48 \%$ severe for ATOMS vs. $11.1 \%$ moderate and $88.9 \%$ severe for AUS; $p=0.0007)$. Differential pad test was higher for AUS ( -470 vs. $-1000 \mathrm{ml} ; p<0.0001)$ and so was ICIQ-SF (15.62 vs. $18.3 ; p<0.001)$, but total dryness (76.5 vs. $66.7 \%$; $p=0.33$ ), social continence ( 90.2 vs. $85.2 \% ; p=0.49$ ) and satisfaction (92.2 vs. $88.9 \% ; p=0.69$ ) were equivalent. The postoperative complication rate was similar (22.6 vs. $29.6 \% ; p=0.4$ ). The surgical revision rate was higher for AUS (6.9 vs. 22.2\%; $p=0.029)$ and also the explant rate but did not reach statistical significance (4.9 vs. $14.8 \%$; $p=0.09$ ). Time to explant was shorter for AUS (log-rank $p=0.021$ ). Regression analysis revealed radiation $(p=0.003)$ and incontinence severity $(p=0.029)$ predict total dryness, while complications $(p<0.005)$ and type of device $(p=0.039)$ independently predict surgical revision.

Conclusions: Both ATOMS and AUS are effective devices. Pad test change for AUS exceeds that of ATOMS. The revision rate is higher for AUS, and durability is superior for ATOMS. The 
satisfaction rate is equivalent. Larger series and longer follow-up are needed to compare both devices more appropriately. According to our experience, the AUS is not the only gold standard for PPI.

Keywords: Adjustable transobturator male system; Artificial urinary sphincter; Effectiveness; Post-prostatectomy incontinence; Safety; Urology

\section{Key Summary Points}

Prospective non-randomized study comparing the efficacy and safety of the adjustable transobturator male system (ATOMS) and artificial urinary sphincter (AUS) for post-prostatectomy incontinence.

Patients treated with AUS had higher baseline pad test weights. Differential pad test and International Consultation on Incontinence Questionnaire-Short (ICIQ$\mathrm{SF}$ ) results were also higher with AUS. This device is preferred for patients with higher severity of sphincteric damage.

At a mean follow-up of 34.9 months no difference was detected in dryness (zero pads per day), social continence (1-2 pads/day), satisfaction with the devices and complications.

The revision rate was higher with AUS, and the explant-free interval was lower, which confirmed better durability for ATOMS.

Regression analysis revealed radiation and incontinence severity predict dryness, while complications and type of device independently predict surgical revision.

\section{DIGITAL FEATURES}

This article is published with digital features, including a summary slide, to facilitate understanding of the article. To view digital features for this article go to https://doi.org/10.6084/ m9.figshare.13187153.

\section{INTRODUCTION}

Prostate cancer is the most frequent malignancy in males, accounting for $21 \%$ of newly diagnosed cancers in males worldwide [1]. Despite notable improvements regarding the aetiology of post-prostatectomy incontinence (PPI) and the surgical technique, this sequel to prostate cancer treatment is still disturbingly high [2].

There are many different treatment options for PPI after failure of conservative therapy. Classically, the gold standard surgical treatment has been the artificial urinary sphincter (AUS), especially for moderate and severe incontinence. This multicomponent hydraulic device circumferentially compresses the bulbar urethra, leading to a risk of atrophy and urethral erosion. Also, the patient manipulation with every micturition contributes to the risk of mechanical failure, which is $>10 \%$ within 4 years [3]. Not surprisingly, the need for surgical reintervention is as high as $26-31 \%$ [4-6], and the dryness rate reported in the mid-term is $58 \%$ [6].

The AMS 800 (Boston Scientific, Marlborough, MA, USA) is by far the most commonly used device; however, in recent years, other devices have emerged, from new artificial sphincters to retrobulbar slings and adjustable devices that exert urethral compression, such as the adjustable transobturator male system (ATOMS), to adjustable continence therapy (pro-ACT) and urethral tensioning, which include the male readjustable mechanical (REEMEX) system and Argus adjustable sling [7]. ATOMS (Agency for Medical Innovations $\mathrm{GmbH}$, Feldkirch, Austria) is composed of a central silicone cushion connected to a port and a two-arm mesh anchored through the transobturator passage on both sides, thus compressing the bulbar urethra only on its ventral 
side and preserving urethral vascularization. It requires no manipulation by the patient and can be adjusted postoperatively in the office by a simple port injection without need for anaesthesia [8, 9]. A meta-analysis revealed treatment with ATOMS resulted in $67 \%$ dryness, 90\% improvement and 5.8\% explantation [10].

Several registries (DOMINO, SATURN) are being conducted with the intention to compare different options to treat PPI, but direct comparative studies between AUS and other devices are lacking, mainly because the ideal patient profile is not the same, making direct randomization difficult. Our objective is to perform a single-centre prospective study comparing the efficacy and safety of ATOMS and AUS in a clinical practice setting, with the intention to evaluate dryness, satisfaction, complications, surgical revision and explant rates in a clinical scenario and thus shed some light on ATOMS as an alternative to AUS for PPI treatment.

\section{METHODS}

\section{Subjects}

A comparative prospective non-randomized study (IDEAL, phase IIa) [11] was conducted with consecutive patients who underwent interventions with an AMS800 AUS or ATOMS with silicone-covered scrotal port (SSP) in a university hospital from January 2014 to June 2019. All procedures were performed by two surgeons (JCA, IA). Follow-up was updated to June 2020. Inclusion criteria were stress incontinence after prostate surgery, refractory to conservative options for $>1$ year. Patient age, use of a previous anti-incontinence device or radiation were not exclusion criteria. The decision to use one or the other device was based on patient preference after counselling with physical examination including a urethral compression test (cough test with and without urethral compression by a sponge on a stick). Cystoscopy was used in all cases to rule out active urethral stenosis or bladder neck stricture. Although not performed routinely, urodynamics were used to rule out obstruction or abnormal detrusor activity, especially in cases with increased post-void volume and predominant detrusor overactivity. Patients with very severe incontinence, extensive sphincteric damage and negative urethral compression test (urine loss not prevented by urethral compression) were counselled to receive AUS. On the other hand, patients with a positive urethral compression test (urine loss during cough prevented by urethral compression) were allowed to receive ATOMS regardless their pad test and the endoscopic severity of sphincter damage. Informed consent was obtained in every case for participation in the study. Surgical technique was performed as originally described. The study was conducted in accordance with the Helsinki Declaration and was approved by the Independent Review Board (CEIm Hospital Universitario de Getafe, A09/18). All subjects provided informed consent to participate in the study.

\section{Variables Evaluated}

Patient data were included in an institutional review board database with patients' characteristics, baseline, operative and postoperative data including patient reported-outcomes (PROs). Continence status, complications, surgical revision, explant and secondary treatment were evaluated every 6 months. Baseline incontinence severity was classified according to the pad count as mild (1-2 pads/day), moderate (3-5 pads/day) and severe ( $>5$ pads/day). Data on follow-up included changes in 24-h pad count and pad test and late postoperative complications with risk of surgical revision and occasionally device explant. Total dryness was defined as patients without pads or using a safety pad/day with $<10 \mathrm{ml}$ in the pad test. Social continence was defined as 1-2 pads/day regardless of the pad test results. Satisfaction with the device was defined in a yes/no fashion. Surgical revision was defined as re-intervention for any cause during follow-up.

PROs included the visual analogue score (VAS) for pain on postoperative day 1 and International Consultation on Incontinence Questionnaire-Short Form (ICIQ-SF) results before surgery. The ICIQ-SF provides a brief and 
robust measure to assess the impact of symptoms of incontinence on QOL and outcome of treatment and deals with frequency (ICIQ item 3 , score $0-5$ ), amount of leakage (ICIQ item 4, score 0-6) and overall impact of incontinence (ICIQ item 5, score 0-10). The ICIQ-SF score is provided by the sum of these items (0-21 score). Operative parameters include surgical time, intraoperative complications and length of admission. Postoperative complications were evaluated according to the Clavien-Dindo classification [12]. Continence status, patient satisfaction and surgical revision were registered during follow-up. All patients had a minimum 1-year follow-up.

\section{Statistical Analysis}

Categorical variables were described by absolute and relative frequencies and continuous variables expressed as mean values and SD or median with IQR. Medians and percentages were compared using Mann-Whitney and chisquare tests, respectively. $P<0.05$ was considered a significant statistical level. Factors affecting total dryness and surgical revision were evaluated by univariate analysis using the hazard ratios and 95\% CI. Variables with significant impact in univariate analysis were evaluated in a multivariate logistic regression model.

Estimation of device durability was performed using the time from ATOMS or AUS surgery to device explant for explanted devices and to the last follow-up for the remaining cases. The Kaplan-Meier analysis method with significance evaluated by a two-sided log-rank test and Cox regression were used. The statistical analysis was developed using Statistical Analysis System 9.4 (SAS Institute Inc., Cary, $\mathrm{NC)}$.

\section{RESULTS}

A total of 129 male patients were included: 102 (79.1\%) treated with ATOMS and 27 (20.9\%) with AUS. Mean follow-up was $34.9 \pm 15.9$ months. Table 1 summarizes the baseline data with medical history, severity of incontinence, and operative and postoperative data. Median age was $70 \pm 6.1$ years, without a difference between groups $(p=0.56)$. The body mass index was lower for patients treated with ATOMS $(p=0.001)$. No significant difference was observed between groups in the proportion of patients with ASA index 3-4 (14.7 vs. 29.6\%; $p=0.14)$ in either the median Charlson index $(p=0.57)$ or the rate of previous pelvic radiotherapy $(p=0.325)$. An equivalent proportion of patients received radical prostatectomy $(p=0.743)$ or previous treatment for PPI $(p=0.24)$. There was a tendency to previous urethrotomy in the AUS group $(p=0.09)$ and to coexisting overactive bladder in the ATOMS group $(p=0.061)$, without reaching statistical significance.

Incontinence before implant was severe in 73 patients $(55.3 \%)$, moderate in $48(37.2 \%)$ and mild in $8(6.2 \%)$. Mean baseline pad count was $5.28 \pm 2.13$ pads/day and mean pad test $731.8 \pm 455.2 \mathrm{ml}$. Baseline incontinence severity distribution before the implant was different between devices: $7.9 \%$ mild, $44.1 \%$ moderate and $48 \%$ severe for ATOMS; $11.1 \%$ moderate and $88.9 \%$ severe for AUS ( $p=0.0007$ ). Consequently, baseline pad count was higher in patients treated with AUS $(p=0.001)$ and so was the baseline pad test $(p<0.001)$. Operative time was also significantly higher for AUS $(p<0.0001)$. The distribution of VAS for pain on postoperative day 1 was equivalent between devices $(p=0.866)$. In the ATOMS group 52 patients $(51.5 \%)$ needed postoperative filling of the system by percutaneous injection of the port, and the mean number of fillings performed was $1.7 \pm 1.6$, reaching a total mean final volume of $17.7 \pm 6 \mathrm{ml}$ in the cushion after adjustment. Mean ICIQ-SF was $16.2 \pm 3.2$, significantly higher for the patients treated with AUS $(p<0.001)$ (Fig. 1).

At last follow-up total dryness (no pad use) was present in 96 (74.4\%), social continence in $115(89.15 \%)$ and satisfaction with the device in 118 (91.5\%). No difference was observed between total dryness $(p=0.326)$, social continence $(p=0.49)$ and satisfaction with the implant $(p=0.698)$ between groups (Table 1 and Fig. 2). Mean postoperative pad count was $0.67 \pm 1.24$ pads/day and mean pad test 
Table 1 Preoperative, operative and postoperative data $(n=129)$

\begin{tabular}{|c|c|c|c|}
\hline & ATOMS $(n=102)$ & AUS $(n=27)$ & $p$ value \\
\hline \multicolumn{4}{|l|}{ Baseline data } \\
\hline Age, years $[$ mean $(S D)]$ & $69.9(6.1)$ & $70.1(6)$ & 0.560 \\
\hline BMI, $n[$ mean $(\mathrm{SD})]$ & $27.1(3.9)$ & $29.7(4)$ & 0.001 \\
\hline Charlson Index, $n$ [median (IQR)] & $5(2)$ & $4(1)$ & 0.572 \\
\hline Radical prostatectomy, $n(\%)$ & $91(89.2 \%)$ & $25(92.6 \%)$ & 0.604 \\
\hline Previous incontinence surgery, $n(\%)$ & $7(6.9)$ & $4(14.8)$ & 0.240 \\
\hline Previous pelvic radiation, $n(\%)$ & $11(10.8)$ & $5(18.5)$ & 0.325 \\
\hline 24-h pad count, $n$ [mean (SD)] & $4.5(2.1)$ & $6.52(2)$ & 0.001 \\
\hline 24-h pad test, ml [mean (SD)] & $613.1(373.6)$ & $1180(462.3)$ & $<0.001$ \\
\hline ICIQ-SF, $n$ [mean (SD)] & $15.62(3.2)$ & $18.3(2.1)$ & $<0.001$ \\
\hline \multicolumn{4}{|l|}{ Operative data } \\
\hline Operation time, min [median (IQR)] & $60(21)$ & $85(30)$ & $<0.001$ \\
\hline VAS scale, $n[$ mean $(\mathrm{SD})]$ & $0.8(1.5)$ & $0.8(1.3)$ & 0.866 \\
\hline \multicolumn{4}{|l|}{ Postoperative data } \\
\hline Surgical revision, $n(\%)$ & $7(6.9 \%)$ & $6(22.2 \%)$ & 0.029 \\
\hline Explant of the device, $n(\%)$ & $5(4.9 \%)$ & $4(14.8 \%)$ & 0.090 \\
\hline Clavien-Dindo complications, $n$ (\%) & $23(22.6 \%)$ & $8(29.6 \%)$ & 0.443 \\
\hline Grade I & $16(15.7 \%)$ & $6(22.2 \%)$ & \\
\hline Grade II & $2(2 \%)$ & $0(0 \%)$ & \\
\hline Grade III & $5(4.9 \%)$ & $2(7.4 \%)$ & \\
\hline Grade IV-V & $0(0 \%)$ & $0(0 \%)$ & \\
\hline 24-h pad count, $n$ [mean (SD)] & $0.57(1.05)$ & $1.04(1.8)$ & 0.223 \\
\hline Differential 24-h pad count, $n$ [mean (SD)] & $-4.38(1.8)$ & $-5.48(2.4)$ & 0.012 \\
\hline 24-h pad test, ml [mean (SD)] & $44.23(98.05)$ & $120.6(293.6)$ & 0.147 \\
\hline Differential 24-h pad test, ml [mean (SD)] & $-569(341.5)$ & $-1060(533.3)$ & $<0.001$ \\
\hline Total dryness*, $n(\%)$ & $78(76.5 \%)$ & $18(66.7 \%)$ & 0.326 \\
\hline Social continence ${ }^{* *}, n(\%)$ & $92(90.2 \%)$ & $23(85.2 \%)$ & 0.490 \\
\hline Satisfaction, $n(\%)$ & $94(92.2 \%)$ & $24(88.9)$ & 0.698 \\
\hline
\end{tabular}

$B M I$ body mass index, ICIQ-SF International Consultation on Incontinence Questionnaire-Short Form, $S D$ standard deviation, TURP transurethral resection of the prostate, VAS visual analogue scale

a Dryness was classified as no pads or one security pad and $<10 \mathrm{ml} /$ day

b Social continence was defined as 1-2 pads/day 


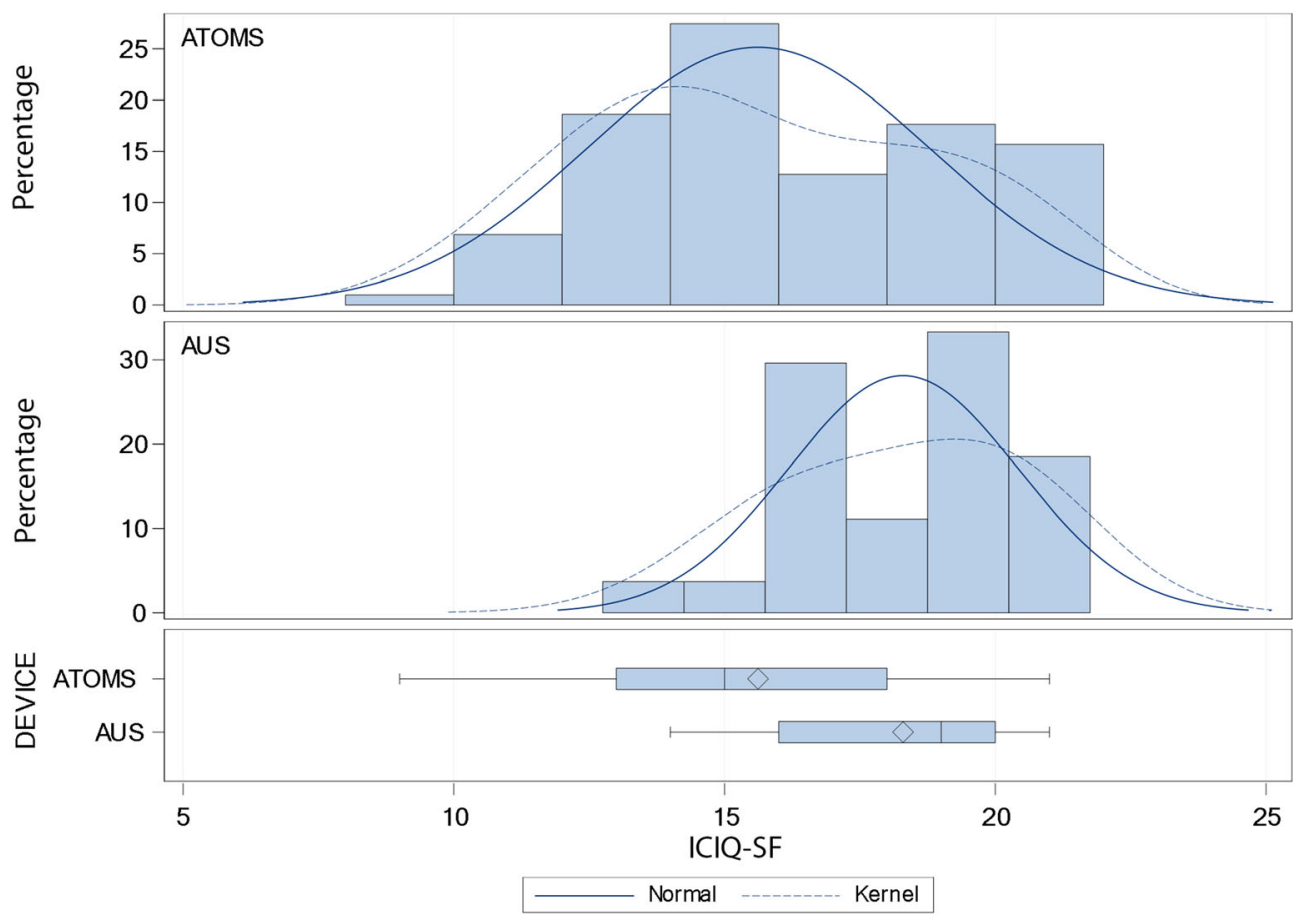

Fig. 1 Distribution of baseline ICIQ-SF

$60.2 \pm 161.4 \mathrm{ml}$. No difference was observed in the postoperative pad count $(p=0.223)$ or pad test $(p=0.147)$ between devices. However, taking into account the baseline differences already reported, mean differential pad count was $-4.61 \pm 2.02$ pads/day and mean differential pad test $-672 \pm 435.9 \mathrm{ml}$. Both the differential pad count and pad test were higher for AUS ( $p=0.012$ and $p<0.0001$, respectively) (Table 1 and Fig. 3). Logistic regression analysis revealed previous radiotherapy (radiation vs. non-radiation, OR 3.97 (95\% CI 1.27-12.5);

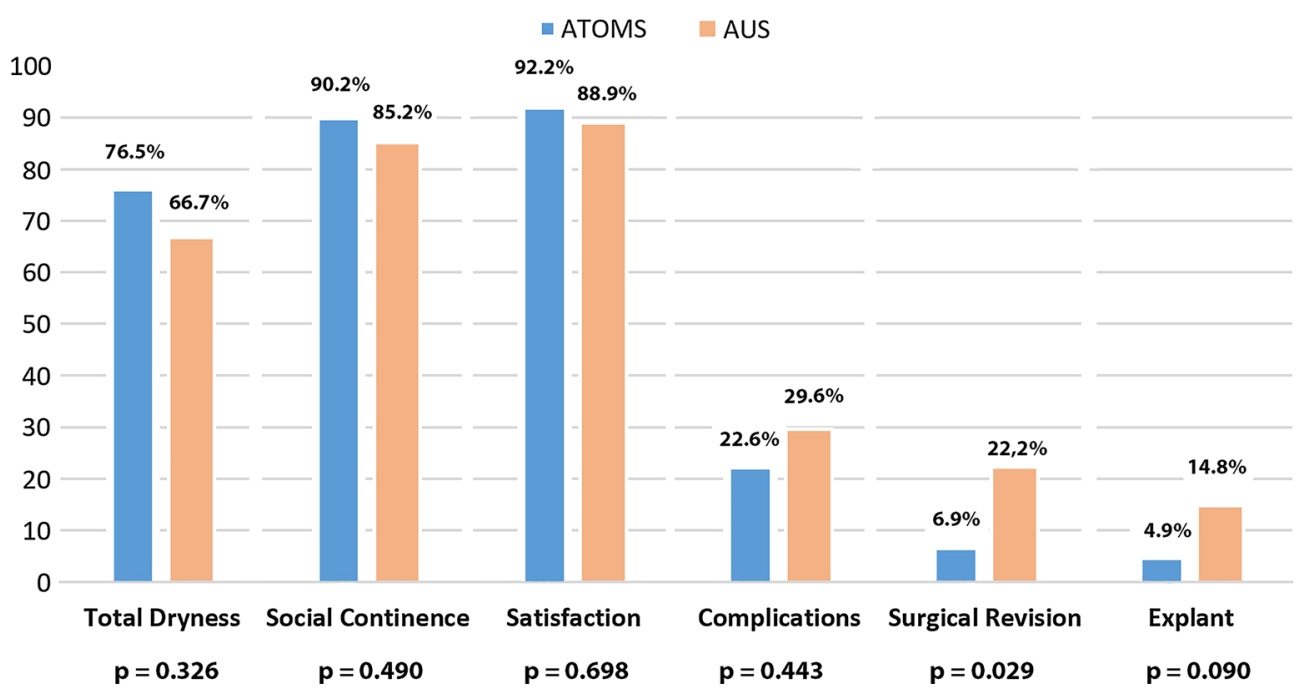

Fig. 2 Proportion of dryness (zero pads or one pad with less than $10 \mathrm{ml}$ ), social continence (1-2 pads/day), satisfaction, complications, surgical revision and explant with ATOMS and AUS 
Table 2 Logistic regression model to predict total dryness (no pad use) with devices used for postprostatectomy incontinence

\begin{tabular}{lllll}
\hline Univariate variables & \multicolumn{3}{l}{ Odds ratio estimates } \\
\cline { 2 - 5 } & OR & $\mathbf{9 5 \%}$ Wald CI & \multicolumn{1}{l}{$\boldsymbol{p}$ value } \\
\hline Radiotherapy compared to no radiotherapy & 4.76 & 1.61 & 14.3 & 0.005 \\
Severe incontinence compared to mild-to-moderate incontinence & 3.88 & 1.54 & 10 & 0.004 \\
Previous treatment of urethral stricture vs. no urethral stricture & 2.78 & 1.08 & 7.14 & 0.034 \\
\hline Multivariate variables & \multicolumn{2}{l}{ Odds ratio estimates } & \\
\cline { 2 - 5 } & OR & $\mathbf{9 5 \%}$ Wald CI & \multicolumn{1}{c}{$\boldsymbol{p}$ value } \\
\hline Radiotherapy compared to no radiotherapy & 3.97 & 1.27 & 12.5 & 0.019 \\
Severe incontinence compared to mild-to-moderate incontinence & 2.89 & 1.09 & 7.69 & 0.033 \\
\hline
\end{tabular}

$p=0.019$ ) and incontinence severity (severe vs. mild-to-moderate PPI, OR $2.89 \quad(95 \% \quad$ CI $1.09-7.69) ; p=0.033$ ) were the only independent predictors of total dryness, while treatment with ATOMS or AUS was not a significant predictor variable (Table 2). The area under the curve (AUC) for this regression model was $72 \%$.

Postoperative complications occurred in 31 patients (24\%): 22 (17\%) grade I, $2(1.6 \%)$ grade II and 7 (5.4\%) grade III. No patient suffered grade IV-V complications. The postoperative complications in the total series and each group are described in Appendix A. As revealed in

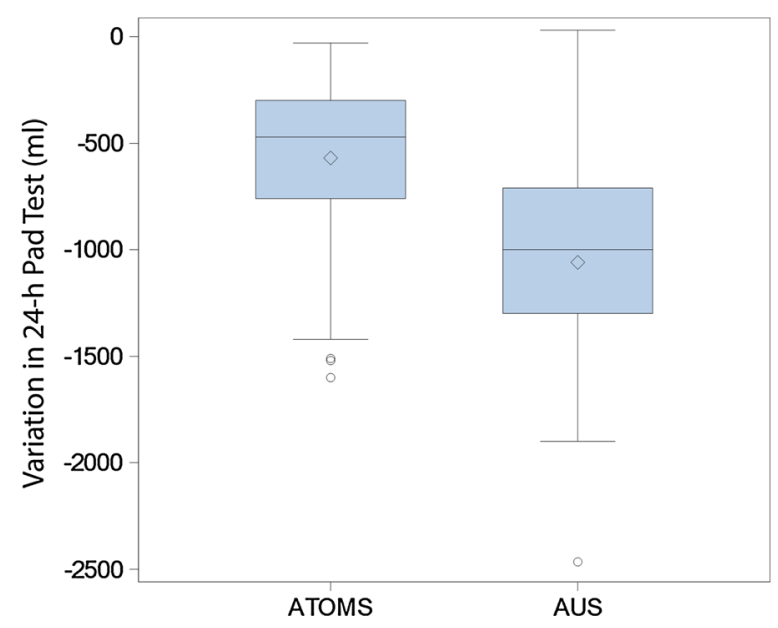

Fig. 3 Differences in variation in 24-hour pad-test (last follow-up minus baseline)
Table 1, the postoperative complication rate within 90 days after surgery was similar between devices $(p=0.443)$. However, in total 13 devices $(10.1 \%)$ needed surgical revision during followup and 9 (7\%) were explanted. The surgical revision rate during follow-up was higher for AUS ( $p=0.029)$ (Fig. 2). We placed a double cuff in one case because of urethral atrophy and a transcorporeal cuff in two more cases for urethral erosion. Logistic regression analysis revealed the type of device [ATOMS vs. AUS, OR 3.96 (95\% CI 1.07-14.65); $p=0.039$ ] and postoperative complications [occurrence vs. not, OR 6.9 (95\% CI 2.64-35.71); $p=0.0006$ ] were independent predictors of an increase in the risk of surgical revision (Table 3). The AUC for this regression model was $81 \%$.

The explant rate was also higher for AUS, but without reaching significance $(p=0.09)$ (Table 1 and Fig. 2). The Kaplan-Meier survival study confirmed the time to explant was shorter for AUS than for ATOMS (log-rank, $p=0.021$ ). Device durability 1 year after the implant was 95\% (95\% CI 88.5-97.9) for ATOMS and 79.5\% (95\% CI 57.1-91.09) for AUS, 2 years after implant 93.3\% (95\% CI 85.5-97.04) for ATOMS and $79.5 \%$ (95\% CI 83.1-91.09) for AUS and 5 years after implant $81.7 \%$ (95\% CI 46.7-94.7) for ATOMS and 69.6\% (95\% CI 40.3-86.5) for AUS (Fig. 4). Cox regression analysis confirmed explant of AUS was more precocious than that 
Table 3 Logistic regression model to predict surgical revision of devices used for postprostatectomy incontinence

\begin{tabular}{|c|c|c|c|c|}
\hline \multirow{3}{*}{$\begin{array}{l}\text { Univariate variables } \\
\text { Postoperative complications occurrence compared to no occurrence }\end{array}$} & \multicolumn{4}{|c|}{ Odds ratio estimates } \\
\hline & \multirow{2}{*}{$\begin{array}{l}\text { OR } \\
9.61\end{array}$} & \multicolumn{2}{|c|}{ 95\% Wald CI } & \multirow{2}{*}{$\frac{\boldsymbol{p} \text { value }}{0.0005}$} \\
\hline & & 2.71 & 34.1 & \\
\hline AUS compared to ATOMS & 3.88 & 1.18 & 12.73 & 0.025 \\
\hline \multirow[t]{2}{*}{ Multivariate variables } & \multicolumn{4}{|c|}{ Odds ratio estimates } \\
\hline & $\overline{\mathrm{OR}}$ & \multicolumn{2}{|c|}{ 95\% Wald CI } & $\overline{p \text { value }}$ \\
\hline Postoperative complications occurrence compared to no occurrence & 6.9 & 2.64 & 35.71 & 0.0006 \\
\hline AUS compared to ATOMS & 3.96 & 1.07 & 14.65 & 0.039 \\
\hline
\end{tabular}

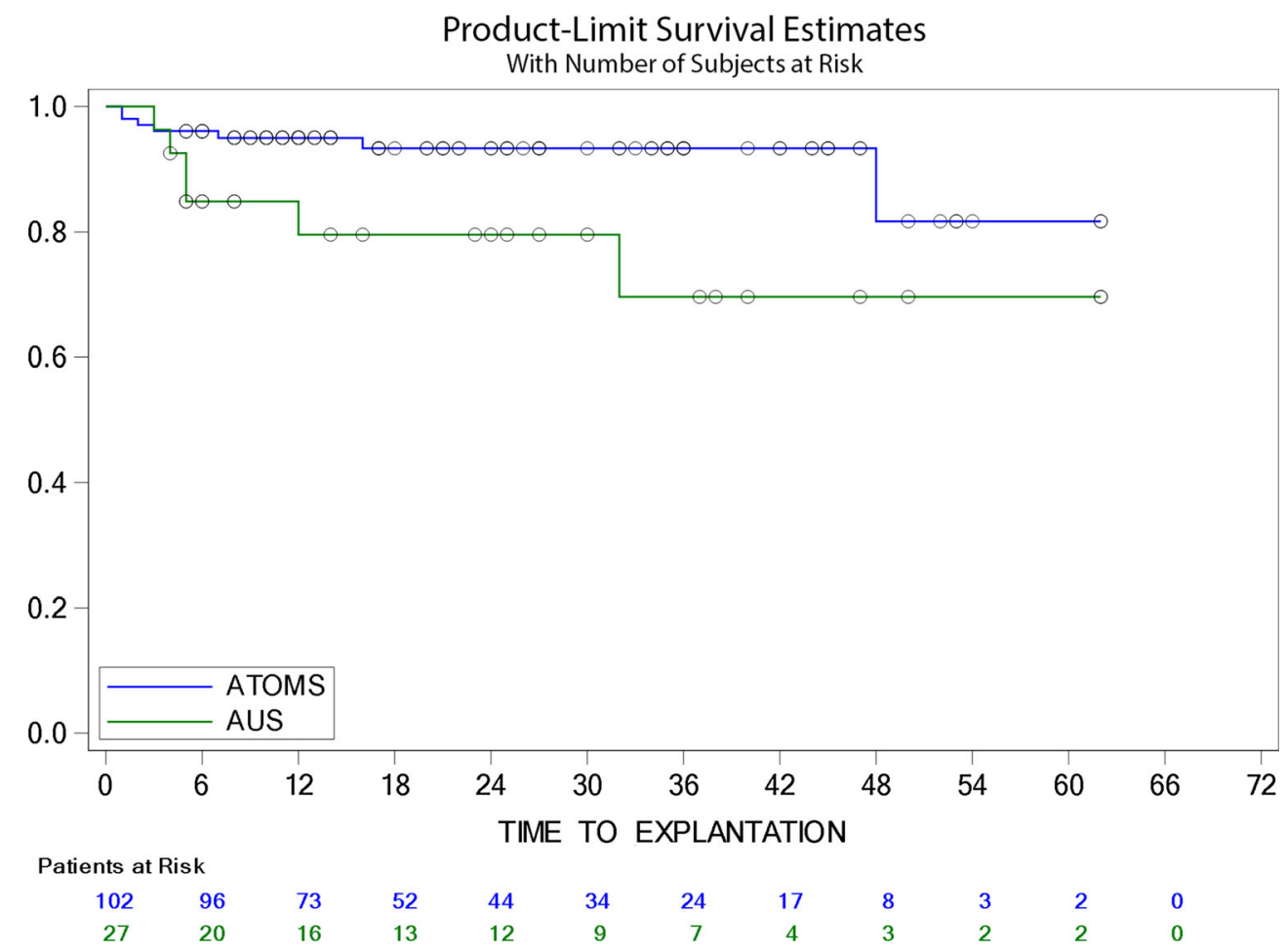

Fig. 4 Kaplan-Meier analysis of the explantation-free interval

of ATOMS (HR 3.3; 95\% CI 1.1-10). Secondary treatment after explant was performed in six cases (2 ATOMS and 4 AUS).

\section{DISCUSSION}

The AUS is the current established standard in the treatment of moderate to severe PPI [13]. However, for several reasons it is not suitable for all patients. The development of less invasive 
techniques potentially offers patients new options for treatment. and among them the ATOMS device is becoming established as an attractive option. Better outcomes have been reported when ATOMS is used in non-severe and non-irradiated cases, but it is also indicated in selected cases with severe incontinence $[14,15]$. ATOMS can be especially considered in patients with impaired cognition, diminished manual dexterity or unwilling to manipulate an AUS as well as patients with recurrent incontinence after a failed sling or AUS and reluctant to repeat the same device [16]. The main advantages of ATOMS reside in its simplicity, no patient manipulation being required, almost absent probability of urethral atrophy or erosion and the possibility of postoperative adjustment. There are few comparative studies of the AUS and the various male slings and occlusive devices. We present to our knowledge the first prospective comparison undertaken between AUS and ATOMS.

The criteria for the selection of the best patients to be treated with ATOMS or AUS are currently a subject of debate and the final decision is influenced by medical and patient preference biases $[13,17]$. Good selection of one or the other device may improve the results of both. Criteria to define the best patient profile can be based on the incontinence magnitude, former irradiation, patient frailty, age, autonomy and manual dexterity $[18,19]$. Physicians offering different treatment options tend to consider AUS in the more complex patient [20]. No decision-assisting algorithm has been developed to help clinicians in the choice to use one device or another, but the cough test has been recently proposed to improve prediction of success in patients undergoing a male sling procedure [21]. In our study, the decision to use one or the other device was based on patient preference and counselling with physical examination and cough test. We did not decide on AUS over ATOMS for cases with former radiotherapy or previous failed incontinence surgery. As can be expected in an aged-population, the proportion of patients electing a device without manipulation is greater. Patients with higher sphincteric deficiency on the cough test, and thereof higher baseline pad test, were counselled to receive an AUS. On the other hand, frail patients with cognitive deterioration and other functional considerations were counselled to receive an ATOMS. Radiotherapy was not considered a contraindication in one or the other device.

The AUS, and more specifically AMS800, is the device with the most experience, but reported results are variable [5]. Recent multicentre international experience has shown dryness in $58 \%$ and surgical revision in $30.7 \%$ of the cases in the mid-term, partly determined by institutional case load [6]. Another recent multicentre long-term study with ATOMS reported a $72.1 \%$ continence rate and $11.6 \%$ explant rate at 5 years [15]. The experience we present confirms both AUS and ATOMS are effective to treat PPI; however, we could not prove superiority of either equivalency for the devices. Differences in terms of total dryness, social continence and patient satisfaction were not observed, but baseline incontinence seveity was different for the devices and the type of device did not have an effect on regression analysis of factors affecting total dryness. The magnitude of the therapeutic effect is larger for AUS, as confirmed by greater baseline ICIQ-SF and pad test improvement, and this suggests patients with more serious sphincteric damage are probably better treated with an AUS. However, ATOMS can be the appropriate choice in a large proportion of patients in daily practice.

From the surgical perspective, the single incision needed to place an ATOMS shortens the operating time, which could also imply an economic advantage. The total number and severity of postoperative complications appear similar, although the safety profile of the two devices differs. We confirm the major complications that can be anticipated for AUS are urethral erosion, urethral atrophy and mechanical failure $[5,6,22]$. On the other hand, the most likely complications for ATOMS are port erosion, infection and postoperative pain $[9,15,23,24]$. One of our findings is that pain in the early postoperative period is very similar with both devices. Most patients treated with ATOMS in this series needed none or one postoperative adjustment, thus reducing the risk of complications associated with device 
manipulation. Urethral erosion should not be expected with ATOMS because the bulbospongiosus muscle is not dissected and a circumferential compression on the urethra is not applied. For this reason, ATOMS is indicated for the fragile urethra when the AUS is at higher risk of problems $[16,25]$.

This inequal security profile can justify differences in the number of surgical revisions. The reintervention rate for AUS in our series was slightly lower than that reported by other authors (26-31.2\%) [4-6]. However, this could depend on the length of follow-up and patient selection bias. Another interesting aspect demonstrated is that the durability of ATOMS in our series is higher than that of AUS. Within the same follow-up the ATOMS system was explanted in $4.9 \%$ of the cases and AUS in $14.8 \%$. Device explant also occurred earlier with AUS. This could be explained, at least in part, because ATOMS uses a single incision (as opposed to a double incision for AUS), has reduced surgical time and the surgical procedure is associated with a short learning curve. Besides, unlike AUS, ATOMS is not prone to suffer mechanical failures.

Although no differences in the efficacy outcomes between devices were found, we cannot say the devices are really equivalent. In fact, a direct comparison was not possible because the baseline pad test differs between devices, and this is an independent predictor of continence in this series. Other limitations of our study are the lack of randomization for patients to receive one or the other treatment and also unequal numbers of patients for the devices evaluated, which could imply worse results in the surgical technique with diminished case load. In fact, better continence results and lower revision rates with AUS have been recently described at high-volume units compared to those with fewer than ten cases per year [26]. Strengths include use of multiple outcome measurements including the 24-h pad test and ICIQ-SF questionnaire.

In our experience both ATOMS and AUS are effective treatments for PPI with similar results in terms of achieving dryness and patient satisfaction. As was demonstrated in the retrospective comparison between AUS and adjustable slings (mixture of Argus and ATOMS) in the DOMINO registry, patients selected for AUS implantation are those with a more severe grade of PPI [27]. The magnitude of therapeutic effect (changes in the 24-h pad test and pad count and ICIQ-SF evaluation) is larger for AUS, as this device is preferred for patients with higher severity of sphincteric damage. However, the surgical revision rate of AUS is also higher and ATOMS seems a more durable device, as can be expected for a simpler mechanism. Data from the DOMINO registry already mentioned also confirm that explant rate is lower with adjustable devices than with with AUS [28]. Of course, larger series with longer follow-up are required to better compare these devices. We believe adjustable devices should not be considered as a whole because the mode of action and also the efficacy and security profile differ among these devices [29, 30].

It was not our intention to perform a costeffectiveness analysis, but considering some of the differences demonstrated between the devices compared, especially the increased operative time and revision rate for AUS, together with the increased cost of the AUS (9.920\$) compared to the ATOMS (5.250\$), an important cost saving can be anticipated for patients treated with ATOMS. Today hospital early discharge is the rule for both devices, and almost all patients stay in the hospital for several hours or overnight. Besides, the readmission rates due to postoperative complications are similar. From an economic perspective, we can conclude treating one patient with AUS is equivalent to treating two patients with an ATOMS. However, we insist that not all patients are candidates for ATOMS. Further insight into a direct prospective comparison between AUS and ATOMS will be welcome and hopefully provided once the ongoing SATURN trial is completed. In the meantime, according to our experience, we cannot consider AUS the only gold standard to treat PPI.

\section{ACKNOWLEDGEMENTS}

We thank the participants of the study. 
Funding. No funding or sponsorship was received for this study or publication of this article.

Authorship. All named authors meet the International Committee of Medical Journal Editors (ICMJE) criteria for authorship for this article, take responsibility for the integrity of the work as a whole, and have given their approval for this version to be published.

Authorship Contributions. All authors have made substantial contributions as outlined by the ICMJE guidelines to the conception or design of the work (Ignacio Arance, Javier Angulo), or the acquisition (Cristina Esquinas, Sonia Ruiz, Ignacio Arance and Javier Angulo), analysis (Cristina Esquinas, Juan Dorado, Miguel Virseda and Javier Angulo) or interpretation of data for the work (Cristina Esquinas, Juan Dorado, Miguel Virseda and Javier Angulo) and drafting the work or revising it critically for important intellectual content (Cristina Esquinas, Sonia Ruiz, Elena de Sancha, Mónica Vazquez, Juan F. Dorado, Miguel Virseda, Ignacio Arance and Javier Angulo).

Disclosures. Cristina Esquinas, Sonia Ruiz, Elena de Sancha, Mónica Vazquez, Juan F. Dorado, Miguel Virseda, Ignacio Arance and Javier Angulo have nothing to disclose.

Compliance with Ethics Guidelines. The study was conducted in accordance with the Helsinki Declaration and was approved by Independent Review Board (CEIm Hospital Universitario de Getafe, A09/18). All subjects provided informed consent to participate in the study.

Data Availability. The datasets generated during and/or analysed during the current study are available from the corresponding author on reasonable request.

Open Access. This article is licensed under a Creative Commons Attribution-NonCommercial 4.0 International License, which permits any non-commercial use, sharing, adaptation, distribution and reproduction in any medium or format, as long as you give appropriate credit to the original author(s) and the source, provide a link to the Creative Commons licence, and indicate if changes were made. The images or other third party material in this article are included in the article's Creative Commons licence, unless indicated otherwise in a credit line to the material. If material is not included in the article's Creative Commons licence and your intended use is not permitted by statutory regulation or exceeds the permitted use, you will need to obtain permission directly from the copyright holder. To view a copy of this licence, visit http://creativecommons.org/licenses/bync/4.0/.

\section{REFERENCES}

1. Siegel RL, Miller KD, Jemal A. Cancer statistics, 2020. CA Cancer J Clin. 2020;70:7-30.

2. Averbeck MA, Marcelissen T, Anding R, Rahnama'i MS, Sahai A, Tubaro A. How can we prevent postprostatectomy urinary incontinence by patient selection, and by preoperative, peroperative, and postoperative measures? International Consultation on Incontinence-Research Society 2018. Neurourol Urodyn. 2019;38(Suppl 5):S119-26.

3. Linder BJ, Viers BR, Ziegelmann MJ, Rivera ME, Rangel LJ, Elliott DS. Artificial urinary sphincter mechanical failures-is it better to replace the entire device or just the malfunctioning component? J Urol. 2016;195:1523-8.

4. Linder BJ, Rivera ME, Ziegelmann MJ, Elliott DS. Long-term outcomes following artificial urinary sphincter placement: an analysis of 1082 cases at Mayo Clinic. Urology. 2015;86:602-7.

5. Van der Aa F, Drake MJ, Kasyan GR, Petrolekas A, Cornu JN, Young Academic Urologists Functional Urology Group. The artificial urinary sphincter after a quarter of a century: a critical systematic review of its use in male non-neurogenic incontinence. Eur Urol. 2013;63:681-9.

6. Tutolo M, Cornu JN, Bauer RM, Ahyai S, Bozzini G, Heesakkers J, Drake MJ, Tikkinen KAO, Launonen E, Larré S, Thiruchelvam N, Lee R, Li P, Favro M, Zaffuto E, Bachmann A, Martinez-Salamanca JI, Pichon T, De Nunzio C, Ammirati E, Haab F, Van Der Aa F. Efficacy and safety of artificial urinary sphincter (AUS): results of a large multi-institutional cohort 
of patients with mid-term follow-up. Neurourol Urodyn. 2019;38:710-8.

7. Kretschmer A, Hübner W, Sandhu JS, Bauer RM. Evaluation and management of postprostatectomy incontinence: a systematic review of current literature. Eur Urol Focus. 2016;2:245-59.

8. Angulo J, Arance I, Esquinas C, Dorado J, Marcelino J, Martins F. Outcome measures of adjustable transobturator male system with pre-attached scrotal port for male stress urinary incontinence after radical prostatectomy. Adv Ther. 2017;34:1173-83.

9. Esquinas C, Arance I, Pamplona J, Moraga A, Dorado JF, Angulo JC. Treatment of stress urinary incontinence after prostatectomy with the adjustable transobturator male system (ATOMS) with preattached scrotal port. Actas Urol Esp. 2018;42:473-82.

10. Esquinas C, Angulo JC. Effectiveness of adjustable transobturator male system (ATOMS) to treat male stress incontinence: a systematic review and meta-analysis. Adv Ther. 2019;36:426-41.

11. McCulloch P, Altman DG, Campbell WB, Flum DR, Glasziou P, Marshall JC, et al. No surgical innovation without evaluation: the IDEAL recommendations. Lancet. 2009;374:1105-12.

12. Dindo D, Demartines N, Clavien PA. Classification of surgical complications: a new proposal with evaluation in a cohort of 6336 patients and results of a survey. Ann Surg. 2004;240:205-13.

13. Hermans B, Van der Aa F. Surgery for male stress incontinence: which technique and when? Eur Urol Focus. 2019;5:310-1.

14. Angulo JC, Cruz F, Esquinas C, Arance I, Manso M, Rodríguez A, Pereira J, Ojea A, Carballo M, Rabassa M, Teyrouz A, Escribano G, Rodríguez E, Teba F, Celada G, Madurga B, Álvarez-Ossorio JL, Marcelino JP, Martins FE. Treatment of male stress urinary incontinence with the adjustable transobturator male system: outcomes of a multi-center Iberian study. Neurourol Urodyn. 2018;37:1458-66.

15. Angulo JC, Virseda-Chamorro M, Arance I, Ruiz S, Ojea A, Carballo M, Rodríguez A, Pereira J, Teyrouz A, Rebassa M, Escribano G, Teba F, Celada G, Madurga B, Martins FE, Mendes PA, Cruz F. Longterm outcome of adjustable transobturator male system for stress urinary incontinence in the Iberian multicentre study. Neurourol Urodyn. 2020;39:1737-45.

16. Angulo JC, Esquinas C, Arance I, Rodríguez A, Pereira J, Rabassa M, Teyrouz A, Teba F, Celada G, Marcelino JP, Martins FE, Manso M, Cruz F. Adjustable transobturator male system after failed surgical devices for male stress urinary incontinence: a feasibility study. Urol Int. 2018;101: 106-13.

17. Comiter CV, Dobberfuhl AD. The artificial urinary sphincter and male sling for postprostatectomy incontinence: which patient should get which procedure? Investig Clin Urol. 2016;57:3-13.

18. Lavi A, Boone TB, Cohen M, Gross M. The patient beyond the sphincter-cognitive and functional considerations affecting the natural history of artificial urinary sphincters. Urology. 2020;137:14-8.

19. Medendorp AR, Anger JT, Jin C, Amin KA, Hampson LA, Lee UJ, Suskind AM. The impact of frailty on artificial urinary sphincter placement and removal procedures. Urology. 2019;129:210-6.

20. Grabbert M, Bauer RM, Hüsch T, Kretschmer A, Kirschner-Hermanns R, Anding R, Brehmer B, Naumann CM, Queissert F, Khoder WY, Gratzke C, Hofmann T, Haferkamp A, Huebner WA. Patient selection in surgical centers of expertise in the treatment of patients with moderate to severe male urinary stress incontinence. Urol Int. 2020;24:1-6.

21. Shakir NA, Fuchs JS, McKibben MJ, Viers BR, Pagliara TJ, Scott JM, Morey AF. Refined nomogram incorporating standing cough test improves prediction of male transobturator sling success. Neurourol Urodyn. 2018;37:2632-7.

22. Kim SP, Sarmast Z, Daignault S, Faerber GJ, McGuire EJ, Latini JM. Long- term durability and functional outcomes among patients with artificial urinary sphincters: a 10-year retrospective review from the University of Michigan. J Urol. 2008;179:1912-6.

23. Mühlstädt S, Angulo JC, Mohammed N, Schumann A, Fornara P. Complications of the urinary incontinence system ATOMS: description of risk factors and how to prevent these pitfalls. World J Urol. 2020;38:1795-803.

24. Friedl A, Mühlstädt S, Zachoval R, Giammò A, Kivaranovic D, Rom M, Fornara P, Brössner C. Long-term outcome of the adjustable transobturator male system (ATOMS): results of a European multicentre study. BJU Int. 2017;119:785-92.

25. Mock S, Dmochowski RR, Brown ET, Reynolds WS, Kaufman MR, Milam DF. The impact of urethral risk factors on transcorporeal artificial urinary sphincter erosion rates and device survival. J Urol. 2015;194: 1692-6.

26. Queissert F, Hüsch T, Kretschmer A, Anding R, Kirschner-Hermanns R, Pottek T, Olianas R, Friedl A, Homberg R, Pfitzenmaier J, Naumann CM, Nyarangi-Dix J, Hofmann T, Rose A, Schweiger J, Hübner W, Loertzer H, Bauer RM, Haferkamp A, 
Schrader AJ. Debates On Male Incontinence (DOMINO)-Project. High/low-volume center experience predicts outcome of AMS 800 in male stress incontinence: results of a large middle European multicenter case series. Neurourol Urodyn. 2020. https://doi.org/10.1002/nau.24444.

27. Grabbert $M$, Hüsch $T$, Kretschmer A, KirschnerHermanns R, Anding R, Rose A, Friedl A, Obaje A, Heidenreich A, Brehmer B, Naumann CM, Queissert F, Loertzer H, Pfitzenmaier J, Nyarangi-Dix J, Kurosch M, Olianas R, Homberg R, Abdunnur R, Schweiger J, Hofmann T, Wotzka C, Pottek T, Huebner W, Haferkamp A, Bauer RM. Comparison of adjustable male slings and artificial urinary sphincter in the treatment of male urinary incontinence: a retrospective analysis of patient selection and postoperative continence status. World J Urol. 2019;37:1415-20.

28. Kretschmer A, Hüsch T, Thomsen F, Kronlachner D, Obaje A, Anding R, Pottek T, Rose A, Olianas R, Friedl A, Hübner W, Homberg R, Pfitzenmaier J,
Queissert F, Naumann CM, Wotzka C, Hofmann T, Seiler R, Haferkamp A, Bauer RM. Debates On Male Incontinence (DOMINO)-Project. Targeting moderate and severe male stress urinary incontinence with adjustable male slings and the perineal artificial urinary sphincter: focus on perioperative complications and device explantations. Int Neurourol J. 2017;21:109-15.

29. Angulo JC, Schönburg S, Giammò A, Abellán FJ, Arance I, Lora D. Systematic review and metaanalysis comparing Adjustable Transobturator Male System (ATOMS) and Adjustable Continence Therapy (ProACT) for male stress incontinence. PLoS ONE. 2019;14(12):e0225762.

30. Angulo JC, Ruiz S, Lozano M, Arance I, Virseda M, Lora D. Systematic review and meta-analysis comparing Adjustable Transobturator Male System (ATOMS) and male Readjustment Mechanical External (REMEEX) system for post-prostatectomy incontinence. World J Urol. 2020. https://doi.org/ 10.1007/s00345-020-03300-1. 